\title{
A DIMENSÃO DO CONCEITO EM DELEUZE E NA ENFERMAGEM ${ }^{1}$
}

\author{
Maria Célia de Freitas ${ }^{2}$ \\ Maria Manuela Rino Mendes ${ }^{3}$
}

Freitas MC, Mendes MMR. A dimensão do conceito em Deleuze e na enfermagem. Rev Latino-am Enfermagem 2004 janeirofevereiro; 12(1):128-33.

O estudo teve como objetivo identificar e analisar o significado de conceito para Deleuze e Enfermagem. O filósofo Deleuze, a partir de um recorte da realidade, cria o conceito, plano de imanência, e para Rodgers, na enfermagem, o conceito surge no momento real que se deseja construir as bases conceituais na Enfermagem. Evidenciou-se, portanto, que o significado de conceito, tanto para Deleuze quanto para Rodgers, embora tenham vivenciado áreas diferentes, tem em comum o acontecimento das coisas e dos seres, que são reflexos da realidade vivida. O conceito, em Rodgers, é caracterizado por seus elementos essenciais, os atributos, e, em Deleuze, pelo que denominou de componentes, ou seja, a essência.

DESCRITORES: formação de conceito; enfermagem; atributos do conceito

\section{CONCEPT DIMENSION FOR NURSING AND DELEUZE}

The study aimed at identifying and analyzing the meaning of concept according to Deleuze, in Philosophy, and Rodgers, in Nursing. Based on an extract of reality, Deleuze creates the concept and calls it "plan of immanence". For Rodgers, in nursing, the concept emerges at the actual moment one wishes to construct the conceptual bases for Nursing. The authors demonstrate that, although Deleuze and Rodgers come from different areas, the meaning they attribute to concept shares the happening of things and beings, which reflect the experienced reality. For Rodgers, the concept is characterized by its essential elements while, for Deleuze, by what he called components, that is, by essence.

DESCRIPTORS: concept formation; nursing; concept attributes

\section{LA DIMENSIÓN DEL CONCEPTO EN DELEUZE y EN LA ENFERMERÍA}

El estudio tuvo como objetivo identificar y analizar el significado de concepto para Deleuze, en la filosofía y Rodgers en la Enfermería. Deleuze, a partir de un recorte de la realidad, crea el concepto y lo denomina "plano de inmanencia". Para Rodgers la idea de concepto surge en el momento en que desea construir las bases conceptuales en la Enfermería. Se evidenció por lo tanto, que el significado de concepto tanto para Deleuze como para Rodgers, aunque hayan evidenciado áreas diferentes, tienen en común el acontecimiento de las cosas y de los seres, que son reflejos de la realidad vivida. El concepto en Rodgers, se caracteriza por sus atributos, elementos esenciales, eventos antecedentes y consecuentes, en Deleuze, solamente por lo que el autor llamó "componentes".

DESCRIPTORES: formación de concepto; enfermería; atributos do concepto

\footnotetext{
${ }^{1}$ Trabalho apresentado na Disciplina: Fundamentos Filosóficos da Educação - Responsável Prof.Dr. Silvio Gallo. Agradecimento especial ao Professor Silvio pela correção e colaboração; ${ }^{2}$ Doutoranda do Programa Enfermagem Fundamental da Escola de Enfermagem de Ribeirão Preto, da Universidade de São Paulo, Professor da Universidade Estadual do Ceará, Enfermeira do Instituto Dr. José Frota, e-mail: celfrei@hotmail.com; ${ }^{3}$ Professor da Escola de Enfermagem de Ribeirão Preto, da Universidade de São Paulo, Centro Colaborador da OMS para o desenvolvimento da pesquisa em enfermagem
} 
INTRODUÇÃO

Deleuze foi o filósofo da multiplicidade e, sobre isso, inicia um dos seus últimos escritos afirmando que "a Filosofia é a teoria das multiplicidades"(1).

Nesse sentido, a Filosofia de Deleuze é uma constante atenção ao mundo e ao tempo presente, em busca dos pequenos detalhes que são os que importam ao fato, não sendo, portanto, uma Filosofia do UNO.

A palavra grega "filosofia" cruza amizade, que remete à proximidade, ao encontro com saber (deleuzianamente, conceito $)^{(1)}$. Esse saber ligado à reflexão e ao conhecimento fundamentado é luta contra a ilusão das opiniões.

Nesse sentido, a Filosofia é um esforço de luta contra a opinião a qual se generaliza e se escraviza com respostas apressadas e soluções fáceis, todas direcionando ao mesmo enfoque; e a luta contra opinião dá-se criando conceitos.

Deleuze, em sua última obra, "O que é a Filosofia?", mergulha na tarefa de construção do conceito, aludindo que o filósofo é amigo do conceito, do conceito em potência. Todavia, não se preocupa o bastante com a natureza do conceito como realidade filosófica. Prefere considerá-lo como conhecimento ou uma representação de dados, que se explicam por faculdades capazes de formá-lo (abstração ou generalização) ou de utilizá-lo (juízo). Mas o conceito não é dado, é criado, está por criar; não é formado, ele próprio se põe em si mesmo, autoposição(2).

Deleuze, utilizando-se do pensamento de Nietzsche, diz que o filósofo não deve contentar-se em aceitar os conceitos que the são dados, para somente limpá-los e fazê-los reluzir, é necessário começar por fabricá-los, criá-los, afirmá-los, persuadindo os homens a utilizá-los ${ }^{(2)}$.

Assim, Deleuze ensina que a Filosofia não é uma simples arte de formar, de inventar ou fabricar conceitos, pois estes não são necessariamente moldes, achados ou produtos. É pois, a disciplina que cria conceito sempre novo, o que passou a ser o objeto da Filosofia ${ }^{(2)}$.

Dessa forma, Deleuze explica que não há conceito simples. Todos têm componentes e se definem por meio deles (...) É uma multiplicidade, embora nem toda multiplicidade seja conceito. Não há conceito de um só componente, mesmo o primeiro conceito. Aquele pelo qual uma Filosofia principia, possui vários componentes, já que não está claro que esta deva ter um "começo" e que, se firmado, deva-lhe ser acrescentado um ponto de vista ou uma razão.

Outras questões também foram refletidas por Deleuze, na referida obra, dentre elas o plano de imanência - recorte da realidade, pois é, a partir dela, que o filósofo cria o conceito, personagens conceituais, functivos e conceitos, prospectivos e conceitos, perceptos, afecto e conceito, todos permeando, continuamente, o conceito.

Assevera-se a importância dos ensaios desse filósofo para a humanidade. Transparência da Filosofia, por meio das noções básicas de conceitos, plano de imanência, personagem conceitual ganham vida nos inúmeros exemplos que se sucedem na obra "O que é a Filosofia?" e, ainda, mesmo que breves, nas análises da instituição da Filosofia, nas obras de Platão, Descartes, Kant, dentre outros ${ }^{(3)}$.

A análise das principais idéias de Deleuze, especialmente a compreensão do conceito, apoiada na obra "O que é a filosofia?", constitui-se o objeto deste ensaio, que pretende, a partir desta interpretação, aproximar a concepção filosófica de Deleuze sobre conceito como multiplicidade, formado e definido por componentes com os constructos do conceito em Enfermagem. Haja vista que cada conceito remete a outros conceitos, não somente em sua história, mas em seu devir ou suas conexões presentes. Para tanto, toma-se como base a discussão de conceito no desenvolvimento deste na Enfermagem, de Beth Rodgers.

Inicialmente, aborda-se a determinação e compreensão deleuziana de conceito, como constituição fundamental da Filosofia, seguida pela apresentação do conceito na Enfermagem, à luz de Rodgers, e, por fim, espera-se construir as relações entre os referenciais escolhidos.

\section{A DIMENSÃO DELEUZIANA DO CONCEITO}

Todo conceito tem uma história e componentes que podem ser tomados também como conceitos. Os conceitos vão ao infinito e, sendo criados, não são jamais criados do nada. Num conceito, há, no mais das vezes, pedaços ou componentes vindos de outros conceitos, que respondem a outros problemas e supõem outros planos ${ }^{(1)}$.

Por conseguinte, todo conceito remete a um problema, pois, sem este, ele não teria sentido, só podendo 
ser isolado ou compreendido na medida de sua solução. Os conceitos contêm três componentes inseparáveis: mundo possível, rosto existente, linguagem real ou fala. Os conceitos expressam o acontecimento, não a essência ou a coisa, e definem-se pela inseparabilidade de um número finito de componentes heterogêneos, percorridos por um ponto em sobrevôo absoluto, à velocidade infinita ${ }^{(2)}$.

Deleuze considera o conceito como o contorno, a configuração, a constelação de um acontecimento por vir (...) É, evidentemente, um conhecimento, mas conhecimento de si, e o que ele conhece, é o puro acontecimento que não se confunde com o estado de coisas nas quais se encarna. Ressaltar sempre um acontecimento das coisas e dos seres é uma tarefa da Filosofia, quando cria conceitos, erigir o novo evento das coisas e dos seres, dar-lhes sempre um novo acontecimento, ou seja, o espaço, o tempo, a matéria, o pensamento, o possível como acontecimentos ${ }^{(2)}$.

Corroborando essa idéia, Gallo define conceito como uma aventura do pensamento que institui um acontecimento ou vários acontecimentos, que permitem um ponto de vista sobre o mundo, sobre o vivido ${ }^{(1)}$.

Entende-se, portanto, que um conceito nunca é criado do nada, mas, sim, de uma multiplicidade de situações; é, então, uma heterogênese. Nesse sentido, um conceito é um acontecimento que desperta interesse e substitui a noção de verdade, na qual passa a ser matéria de apropriação. Alimenta-se das mais variadas fontes: ora do mundo filosófico, ora do mundo da ciência, ora do mundo da arte e, dentro dessas diferentes visões, passa a ter seus significados de acordo com o referencial vivido, já que criar conceitos é produzir realidade.

Contudo, um conceito pode ser entendido como evento/acontecimento do quotidiano, que se produz na mente e permite um ponto de vista do real (produzido/ fabricado). Exige, para sua criação, não apenas a existência do problema, sob o qual remaneja ou substitui conceitos precedentes, mas uma encruzilhada de problemas que se aliam a outros conceitos existentes ${ }^{(2)}$.

Em uma das ilustrações, Deleuze explica que o conceito de pássaro não está em seu gênero ou espécie, mas na composição de suas posturas, das suas cores e cantos. Sendo esta uma, justificativa para a heterogênese do conceito, vê-se que ele é ordenado por vários componentes e está em estado de sobrevôo com relação a estes, mas sem nenhuma distância, passa e repassa por eles - acontecimento e multiplicidade ${ }^{(2)}$.

\section{A DIMENSÃO DO CONCEITO NA ENFERMAGEM}

A Enfermagem, mesmo reconhecendo que o conceito é o objeto da Filosofia, interessa-se em fazer essa apropriação e discussão, motivada pela necessidade de definir e compreender conceitos, a fim de utilizá-los na comunicação com seus pares. Tem interesse, também, na utilização de termos precisos, objetivando a ampliação de conhecimento dos seus exercentes, para que percebam que o sentido das palavras tem uma certa ligação com sua história ou origem, considerando-se as palavras como símbolos, cujos significados são estabelecidos pelo uso, costume ou por associação.

Nesse sentido, afirma-se que, ao definir conceito, busca-se o seu significado. A definição indica o sentido de um termo, da palavra que designe a essência, sendo que o seu conhecimento facilita o processo de comunicação e a compreensão dos fenômenos, bem como a diferenciação do conceito ${ }^{(4)}$.

Observa-se, portanto, que a formação de um conceito requer um conjunto de significados e significantes. O significado consiste na forma lingüística utilizada para expressar a imagem mental geral; o significado se refere à compreensão das propriedades gerais do conceito ${ }^{(5)}$.

A exemplo, cita-se o significante "revista" que consiste no instrumento lingüístico para transmitir a imagem mental de "revista"; o significado é formado pelas propriedades que fazem dela "revista" e não "livro" - é a essência. Para se obter a essência de qualquer conceito, é necessário analisar diferentes conceitos e compará-los.

$\mathrm{Na}$ Enfermagem, o estudo de conceito ascendeu com Rodgers, nos anos de 1989 e 1993, que o despertou para compreender a natureza da Enfermagem, além de outras questões e problemas, considerados como conhecimentos básicos. Para a referida autora, a Enfermagem utilizava terminologias vagas e ambíguas no seu quotidiano, motivo que a fez investir nessa direção ${ }^{(6-}$ 7).

Rodgers, em investigações apoiadas em princípios filosóficos (Descartes, Kant e Locke), identificou que muitos problemas na Enfermagem eram provenientes de questões conceituais. Essas observações favoreceram a busca e o investimento nos conhecimentos filosóficos, possibilitando ampliar sua visão também para a área da Enfermagem e criar propostas para romper essas barreiras de linguagem ${ }^{(6-}$ 7). 
Com tal propósito, a autora elaborou o estudo do conceito com uma visão evolucionária, (Figura 1), representando o movimento contínuo do conceito através do tempo, inserido num dado contexto (realidade) e referido numa disciplina, grupo cultural ou referencial teórico.

Esse ciclo apresenta três distintas influências no desenvolvimento do conceito, denominadas "significado" (significance), "uso" (use) e "aplicação" (application) do conceito.

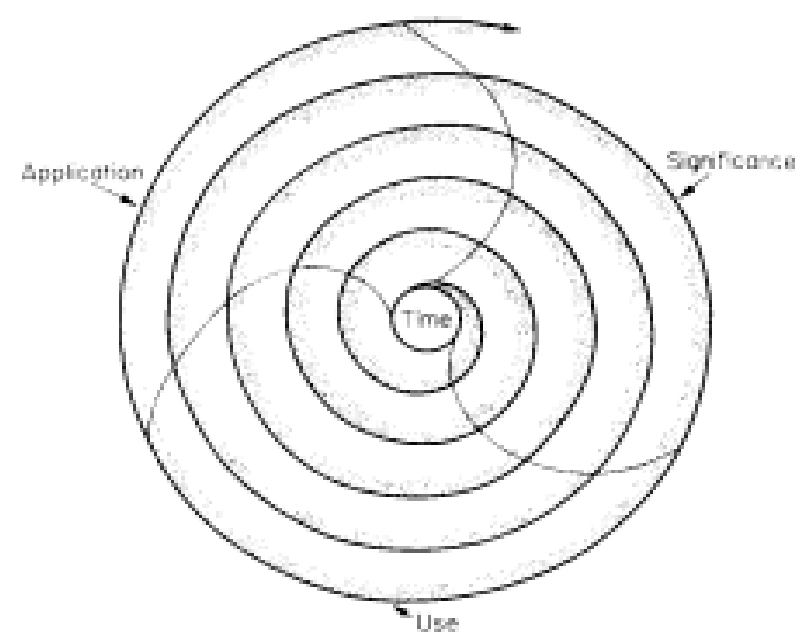

Figura 1 - Ciclo do desenvolvimento do conceito $^{(7)}$

O conceito adquire "significado" através do seu uso e aplicação a cada situação no tempo, influenciado por fatores internos e externos que ampliam, refinam e caracterizam, adequadamente, esse conceito.

$\mathrm{E}$, reportando-se às idéias de Deleuze, quando afirma que o conceito se transforma e é transformado nas suas relações com outros conceitos e com o mundo ${ }^{(6-7)}$, afirma que, nesse caso, o conceito está sendo influenciado por fatores internos e externos.

O "uso" do conceito expressa a maneira pela qual é aplicado em situações apropriadas, expressando "atributos essenciais", que, segundo Deleuze, são também denominados "componentes", relevantes pela linguagem em suas diversas naturezas.

A "aplicação" revela-se quando um conceito está associado ao "uso" em particular e cuja compreensão difunde-se na interação social. Ela reflete o conceito efetivado e identificado no contexto, em que passa a ser continuamente refinado, incorporando outros significados. A "aplicação" revela não somente o fortalecimento do conceito, mas suas limitações.

Para melhor compreensão, toma-se como exemplo a palavra "livro", que "significa" obra literária com publicações de pesquisas. Seu "uso" denota aquisição de conhecimento, tem o sentido de conhecer; e "aplicação" seria a utilização o livro como estratégia pedagógica, servindo de referência de conhecimento para melhorar o cuidado de Enfermagem, como fonte de referência.

Nessa busca para responder aos problemas identificados nas bases de conhecimento da Enfermagem, Rodgers definiu conceito como uma representação mental da realidade que sofre influência da interação social, por meio da aquisição de novos conhecimentos, motivados, também, por fatores internos e externos, que ofereçam possibilidades de refiná-la.

O conceito reflete as representações cognitivas, abstratas, da realidade, percebidas e formadas pelas experiências diretas e indiretas ${ }^{(8)}$. A representação é uma síntese cognitiva dotada de qualidades com globalidades, coerência, constância e estabilidade. Pode-se retrabalhála, recomportá-la e, além disso, cogitá-la e recogitá-la, pois toda representação é acompanhada, explícita ou implicitamente, por palavras e idéias que exercem sobre aquelas análises e sínteses ${ }^{(9)}$.

Nesse sentido, considera-se conceito como imagens de objetos ou ações. Não são as coisas ou ações, mas, simplesmente, as imagens destas ${ }^{(10)}$.

Entende-se, ainda, o conceito como uma representação mental complexa, elaborada a partir de experiências empíricas, que precisam ser analisadas para identificarem os atributos essenciais ${ }^{(11)}$. É o produto de um processo morfogenético e sintético que a constrói sob a forma de imagem global, imediatamente percebida com visão objetiva das coisas reais e apropriação subjetiva dessa visão objetiva (toda percepção comporta um implícito "eu percebo"). Na apropriação mental do objeto, agrupamse dados para elaborar um conceito, sendo este o fim da operação mental que se concretiza sensivelmente ${ }^{(9)}$.

A partir das diferentes visões sobre o entendimento de conceito, Rodgers elaborou estratégias para analisar as palavras/expressões apreendidas da Enfermagem, a fim de que estas fossem usadas com significados e significantes apropriados, conforme uma essência.

Para proceder à análise, organizaram-se as seguintes fases: identificar o conceito de interesse e expressões associadas; identificar e selecionar campo apropriado para a coleta de dados; coletar dados, reconhecendo atributos do conceito junto a termos substitutos, e relacionando antecedentes e conseqüentes; analisar os dados e identificar características do conceito; 
identificar antecedentes, conseqüentes e termos substitutos; identificar caso-modelo do conceito; identificar hipóteses e implicações para outros estudos ${ }^{(6-7)}$.

Tal análise de conceito é um procedimento lingüístico formal, capaz de determinar os atributos essenciais do conceito ${ }^{(12)}$.

Pode-se, portanto, afirmar que a "análise de conceito" proposta por Rodgers constitui-se uma estratégia adequada para investigar, caracterizar e ilustrar "conceito de interesse", utilizando-se o ciclo de desenvolvimento do conceito, vislumbrando-se a possibilidade de vir a contribuir com a prática, pesquisa e educação dos profissionais da saúde, principalmente os da Enfermagem.

\section{A RELAÇÃO ENTRE O SENTIDO DO CONCEITO DE DELEUZE E A ENFERMAGEM}

Deleuze, ao se referir à reflexão de conceito, preocupa-se em dizer que todo conceito remete a um ou mais problemas, sem os quais o conceito não teria sentido, podendo estes serem isolados ou compreendidos na medida de sua solução, estando, dessa maneira, diante de um problema concernente à pluralidade dos sujeitos, à sua relação e apresentação recíproca. Reafirma, portanto, que o conceito não surge do nada, mas de problemas da realidade que considera mal vistos ou mal colocados.

Na compreensão do autor citado, o conceito não é discursivo, e também a filosofia não é uma formação discursiva, porque não encadeia proposições. É, pois, a confusão do conceito e da proposição que leva a se acreditar na existência de conceitos científicos, considerando-se a proposição como uma verdade "intenção". Sendo assim, o conceito filosófico só aparece despido de sentido.

$\mathrm{Na}$ enfermagem, foi a busca de sentido e significado das palavras que trouxe 0 interesse em compreender as questões conceituais e a necessidade de saber analisá-las, identificando aquilo que denominou ser essencial nos conceitos - os atributos, que, para Deleuze, são chamados componentes ${ }^{(2,6-7)}$.

O sentido de conceito, preconizado pela autora mencionada, como já relatado, tem fundamentação na Filosofia, sendo discutida, também, a necessidade de falar sobre conceito a partir da problematização de um acontecimento.

Para os autores ${ }^{(2,6-7)}$, é a necessidade de discutir a existência de problemas/necessidades concernentes à realidade favorece a sua criação. Ambos concordam que essa criação de conceito não se dá de forma única, mas por meio de multiplas associações de situações.

Esse fenômeno, chamado de plano de imanência, é entendido como um recorte da realidade, a partir do qual o filósofo cria o conceito ${ }^{(2)}$.

Desse modo, e considerando Deleuze como o filósofo que responde à questão: "O que é um conceito?", seu referencial foi o suporte escolhido para a interpretação compreensiva do conceito, à luz de Rodgers, na Enfermagem.

A autora ${ }^{(6-7)}$ define conceito como uma representação mental e geral da realidade. Mental, porque não é a realidade em si mesma, mas uma imagem mental dela, e geral, porque contém características de determinada classe da realidade, com, por exemplo: caneta, computador, homem. Diz, ainda, que são acontecimentos dinâmicos, dependentes do contexto, e, na Enfermagem, essa compreensão é importante por ser o enfermeiro essencialmente um cuidador do ser humano, que está em constantes mudanças, pois é um ser dinâmico.

No pressuposto básico apresentado pela autora ${ }^{(6-}$ ${ }^{7)}$, a análise do conceito na Enfermagem é valiosa porque dá possibilidade de solucionar os problemas de palavras e expressões usadas na área, tão essenciais na comunicação precisa, podendo, ainda, por meio dela, ocorrer a construção de conhecimentos.

Por conseguinte, o que interessa na Enfermagem é a elaboração do pensamento crítico, como componente essencial de uma comunicação precisa, e o entendimento teórico e conceitual. Concebe-se, por conseguinte, que essa construção de novos conhecimentos poderá ocorrer por meio da análise de conceito, e de metodologia elaborada pela autora ${ }^{(6-7)}$.

Entretanto, ao se considerarem, aqui, os discursos das literaturas, como também os do quotidiano das enfermeiras, no que se refere ao conceito, pensa-se na necessidade de aprimorar, ainda, outros exercícios de análise já elaborados por Rodgers, como também tentar associá-los a fundamentações filosóficas contemporâneas. Embora estudassem em áreas diferentes, os ideários de Rodgers perpassam os de Deleuze, quando se refere ao conceito como acontecimento, originado de problemas advindos das realidades vividas pelas pessoas, podendo transformar-se e ser transformado na relação com outros 
conceitos e com o mundo.

De fato, parece existirem alguns pontos que se assemelham entre os autores e que devem ser debatidos, para melhor fundamentarem os discursos conceituais, principalmente na Enfermagem, tendo sempre como meta a construção estruturada de conhecimentos.

\section{CONSIDERAÇÕES FINAIS}

Em princípio, pareceu impossível encontrar eixo para articular o pensamento do filósofo Deleuze na Enfermagem, ainda porque em nenhum momento da discussão sobre "O que é um conceito?" ficou explicita uma definição de conceito, como se encontra na Enfermagem.

No texto, o autor utiliza-se de linguagem metafórica e de exemplos, para falar não do conceito como realidade filosófica, mas para considerá-lo como conhecimento ou representação de dados, que se explicam por faculdades capazes de formá-los (abstração ou generalização) ou de utilizá-los (juízo). Dessa forma, é na própria apreensão subjetiva que a representação é percebida como presença objetiva da realidade das coisas, agrupando variações de dados para concretizar o conceito.

No entanto, parece oportuno fazer frente a essas dificuldades e resgatar o entendimento de Rodgers sobre o conceito, independente de suas fases de análise, principalmente quando a autor diz que o conceito advém de um acontecimento da realidade, proveniente da prática

\section{REFERÊNCIAS BIBLIOGRÁFICAS}

1. Gallo S. Notas deleuzianas para uma Filosofia da Educação. In: Ghiraldelli P Jr. (org.) et al. O que é Filosofia da Educação? Rio de Janeiro (RJ): DP\&A, 2000. p.157-184.

2. Deleuze G, Guatarri F. O que é a Filosofia? Trad. Bento Prado Jr. e Alberto Alonso Muñoz. Rio de Janeiro (RJ): Editora 34, 1991

3. Prado-Junior BP. Prefácio. In: Deleuze G, Guatarri F. O que é a Filosofia? Trad. Bento Prado Jr. e Alberto Alonso Muñoz. Rio de Janeiro (RJ): Editora 34, 1991. p.1-2

4. Polak YNS. Análise do conceito de enfrentamento - revisão da literatura. Florianópolis, 1998. 22p. Universidade Federal de Santa Catarina. Mimeografado.

5. Trentine M, Paim L. Pesquisa em enfermagem - uma modalidade convergente-assintencial. Florianópolis (SC): Editora da UFSC, 1999. p.56-58. quotidiana. Ancorando-se nessa idéia, despertou-se para um olhar mais acentuado aos escritos e exemplos de Deleuze, permitindo encontrar pistas e favorecendo reflexões acerca da dimensão do conceito para os referidos autores.

Dessa forma, evidenciou-se que o significado de conceito, tanto para Deleuze quanto para Rodgers, embora tenham vivenciando áreas diferentes, tem em comum o acontecimento das coisas, dos seres, que são reflexos da realidade vivida, identificados através de seus atributos essenciais, para Rodgers, e de seus componentes, para Deleuze.

Para Deleuze, a partir de um recorte da realidade, o filósofo cria o conceito (plano de imanência) e, para Rodgers, a necessidade surge no momento real que se deseja construir as bases conceituais na Enfermagem ${ }^{(2,6-}$ 7).

Portanto, esse novo olhar possibilita a recondução ao ponto inicial, porém com conhecimento ampliado e, talvez, com a proposta de mudar o caráter das discussões quanto à dimensão do conceito, levando-se em consideração a proposta de Rodgers para análise de conceitos como metodologia de pesquisa.

$\mathrm{E}$, assim, por meio das observações apreendidas, estudadas e refletidas no quotidiano vivido, acredita-se que seja possível explicar a natureza da Enfermagem, definir seu campo específico e sua metodologia científica, em contínuo acordo com os componentes preconizados por Deleuze, uma vez que ele se propôs a responder sobre "que é um conceito?"

6. Rodgers B. Concepts, analysis and the development of nursing knowledge: the evolutionary cyclo. Journal of Advanced Nursing 1989; 14:330-5.

7. Rodgers B. Concept analysis: an evolutionary view. In: Rodgers B, Knafl KA. Concept development in nursing: foundations, techniques and applications. United States, W.B. Saunders;1993. p.73-92.

8. Morse JM. Exploring the theoretical basis of nursing advanced techiques of concept analysis. Advs Nurs Sci 1995; 17(3):31-46.

9. Morin E. O método 3. O conhecimento do conhecimento. Porto Alegre (RS): Sulina, 1999. p.96-128.

10. Kemp VH. Concept analysis as a strategy of critical thinking. J Nours Education 1985; 24:425-428.

11. Chinn PL, Kramer M. A model for theory developmente in nursing. Adv Nurs Science 1978; 1(1):1-11.

12. Walker LO, Avant KC. Strategies for theory construction in nursing. Norwalk: Appleton-Century-Crofts;1983. 